\title{
Mapping the Sea-Floor Geology Offshore of the New York-New Jersey Metropolitan Area
}

\section{Introduction}

The U.S. Geological Survey (USGS) is mapping the sea floor offshore of major metropolitan centers. The New York-New Jersey metropolitan area is one of the most populated coastal regions in the United States. The New York harbor estuary and its offshore area are used for waste disposal, transportation, recreation, and commercial and recreational fishing.

Interpretive maps of the sea-floor geology provide a fundamental framework for research and management in the coastal ocean. They show the composition of the seabed and the shape (topography) of the sea floor; they also show areas of present and past dumping of sediments and pollutants, as well as locations and impacts of other human activities. They provide information on the transport of sediment and help to define biological habitats. All this information can be used to develop predictive models to guide habitat and resource management, monitoring strategies, and other research studies.

\section{Mapping the Sea Floor}

Modern oceanographic surveys use remotesensing techniques (sidescan sonar (fig. 1), multibeam echosounding (fig. 2), and high-resolution seismic-reflection profiling), direct sampling, and visual observations to characterize the sea floor. The surveys provide a new, highly detailed view of the sea floor. In contrast to earlier maps that were based on widely spaced data, the new digital images are similar in detail to an aerial photograph and show the changes in seabed features over a wide range of scales. The locations and effects of human activities, such as waste disposal and bottom trawling, are often clearly observed. Sedimentary features, such as bed forms, provide information about the transport and fate of sediments and pollutants and about the importance of the underlying geologic structures and the geologic history in controlling the present distribution of surface sediments.

\section{Mapping the Area Offshore of New York and New Jersey}

Sidescan sonar and multibeam systems emit pulses of sound that reflect off the sea floor. Features of the sea floor are identified by the pattern and varying levels of sound reflected (backscattered) from the sea floor.
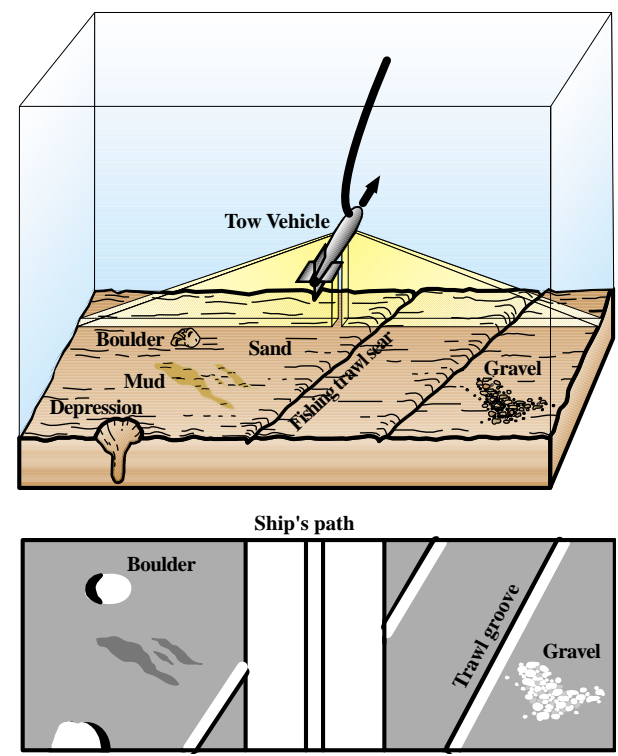

Figure 1. Upper: A sidescan sonar "fish" towed behind a vessel surveys the sea floor by sending sound to either side of the ship's path. Typical survey swaths (yellow area) are a few hundred meters wide. Lower: The intensity and pattern of sound reflected from the ocean floor provide information on the composition of sediments and the topography. Strong reflections from boulders, gravel, and the walls of trawl grooves appear as light tones on this data record; weak reflections from finer sediments or shadows behind vertical features are dark. A composite image, pieced together from multiple survey strips, provides an image of the sea floor similar in detail to an aerial photograph.

One of the most striking characteristics of the backscatter maps of the New York Bight area (fig. 3) is the variability in sediment characteristics over scales of tens to hundreds of meters. Sampling, bottom photography, and the high-resolution seismic observations show that the bottom sedimentary environments in this area range from outcropping rock to muds. The maps show a complex pattern of sediment properties that is a result of the underlying geology, modern processes, and anthropogenic activities.

The surveys off the New York-New Jersey area are being carried out by the USGS in cooperation with the U.S. Army Corps of Engineers, Texas A\&M University, the State University of New York at Stony Brook, the University of New Brunswick, the Canadian Hydrographic Service, Wesleyan University (Connecticut), and Coastal Carolina University.

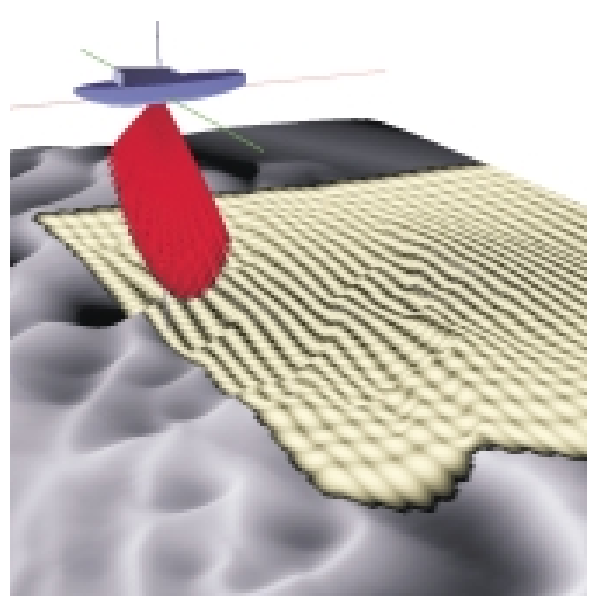

Figure 2. High-resolution multibeam mapping systems use sound from arrays of 60 to more than 150 electronically separated transducers to measure water depth as well as sediment characteristics of the sea floor. The transducers form beams a few degrees wide that produce a footprint of a few square meters on the sea floor in water depths of 50 meters. Because the system is fixed to the ship's hull, the data can be easily georeferenced and surveys can be run at speeds of 15 knots. The multibeam surveys provide a new, highly detailed view of the sea floor. Used with the permission of the University of New Brunswick.

\section{References Cited}

Butman, Bradford, Danforth, W.W., Schwab, W.C., and Bucholtz ten Brink, M.R., 1998, Seafloor topographic and backscatter maps of the Upper Hudson Shelf valley and adjacent shelf, offshore of New York: U.S. Geological Survey Open-File Report 98-616.

Schwab, W.C., Allison, M.A., Corso, W. Lotto, L.L., Butman, B., Bucholtz ten Brink, M., Denny, J., Danforth, W.W., and Foster, D.S., 1997, Initial results of highresolution sea-floor mapping offshore of the New York - New Jersey metropolitan area using sidescan sonar: Northeastern Geology and Environmental Sciences, v. 19 , no. 4 , p. 243-262.

For more information, please contact:

Bradford Butman

U.S. Geological Survey

Woods Hole Field Center

384 Woods Hole Road

Woods Hole, MA 02543-1598 


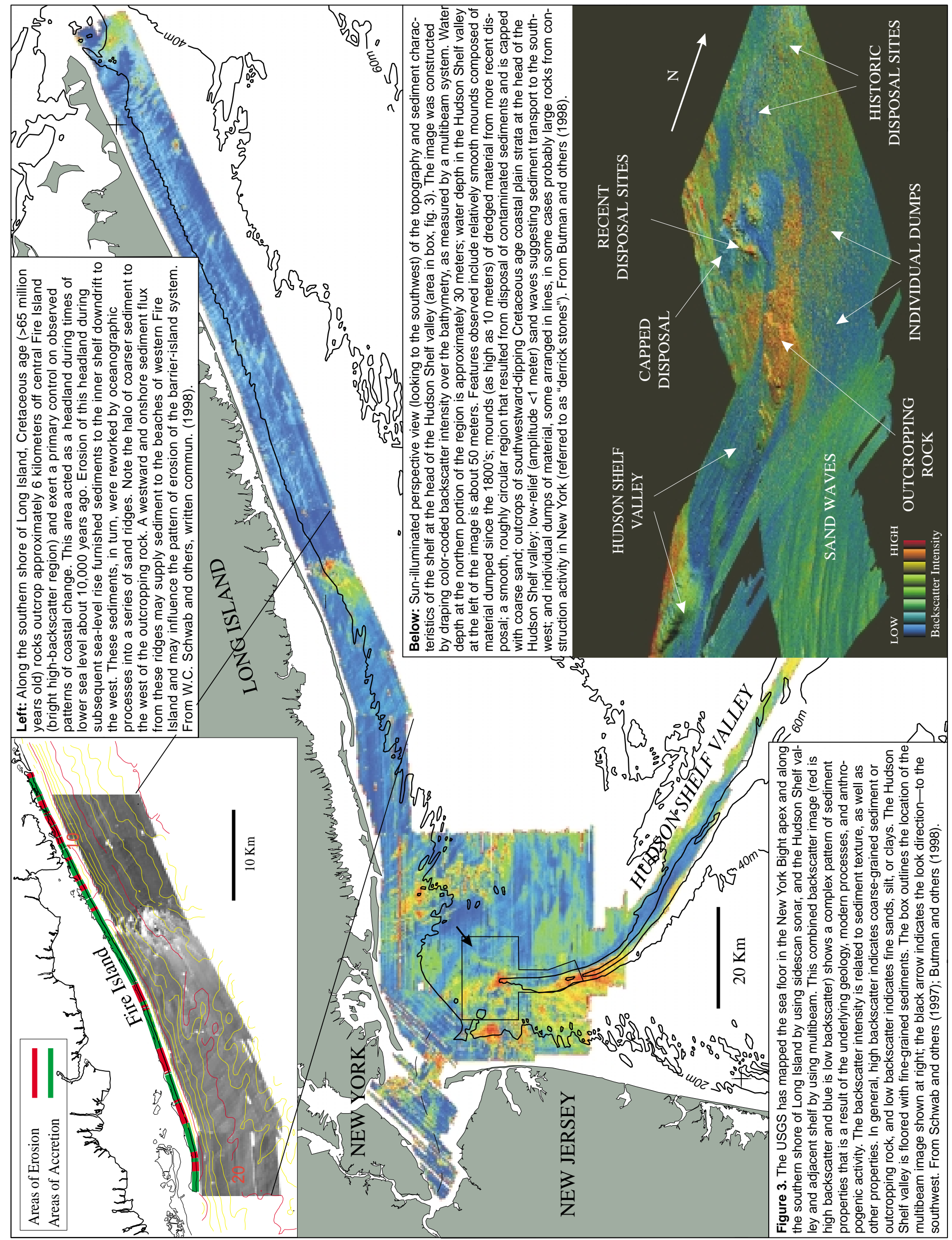

